\title{
Quyền từ chối trích dẫn - phải chăng là một sự đi ngược lại với văn hoá trích dẫn khoa học?
}

- $16: 32,08 / 05 / 2021$

- Thông tin khoa học

-

Một nghiên cứu - công bố về một vấn đề hiếm gặp về quyền từ chối trích dẫn trên tạp chí Scientometrics (Nhà xuất bản Springer).

Bài liên quan

- Xuất bản sách không còn chỗ đứng trong cuộc chạy đua xếp hạng đại học

- Một số vấn đề lý luận và thực tiễn về chủ nghĩa xã hội và con đường đi lền chủ nghĩa xã hội ở Việt Nam

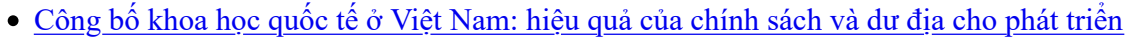

Về mặt logic, và theo hầu hết các tiêu chuẩn chung, các học giả sẽ rất vui khi được trích dẫn, coi đó là một hình thức công nhận trí tuệ của họ. Đổi lại, đặc biệt là những người có số lượng trích dẫn cao, có thể hưởng lợi thông qua sự công nhận của đồng nghiệp, phần thưởng, tài trợ, đảm bảo vị trí tốt hơn hoặc mở rộng mạng lưới cộng tác.

Trong khi phần lớn các cuộc trò chuyện học thuật xung quanh các trích dẫn xoay quanh nhu cầu được trích dẫn, lợi thế của trích dẫn đối với tác giả hoặc tạp chí hoặc việc lạm dụng hoặc thao túng các trích dẫn. Hơn nữa, bất chấp những lợi ích đã biết và chưa kề, một vấn đề vẫn chưa được thảo luận: quyền tù̀ chối trích dẫn.

Thật vậy, các học giả có thể không muốn được trích dẫn bởi các bài báo được xuất bản trên các tạp chí có chất lượng thấp, có tính "săn mồi”, bài báo có tác giả giả mạo hoặc bài báo châm biếm với các yếu tố giả mạo sử dụng các thủ thuật đạo đức mờ ám. Hiện tại, các học giả thường có quyền tự do lựa chọn nơi họ xuất bản các liên kết của mình và chọn các nghiên cứu mà họ trích dẫn, vì vậy rất có thể yêu cầu xóa trích dẫn hoặc từ chối trích dẫn có thể không bao giờ trở thành một chính sách xuất bản chính thức.

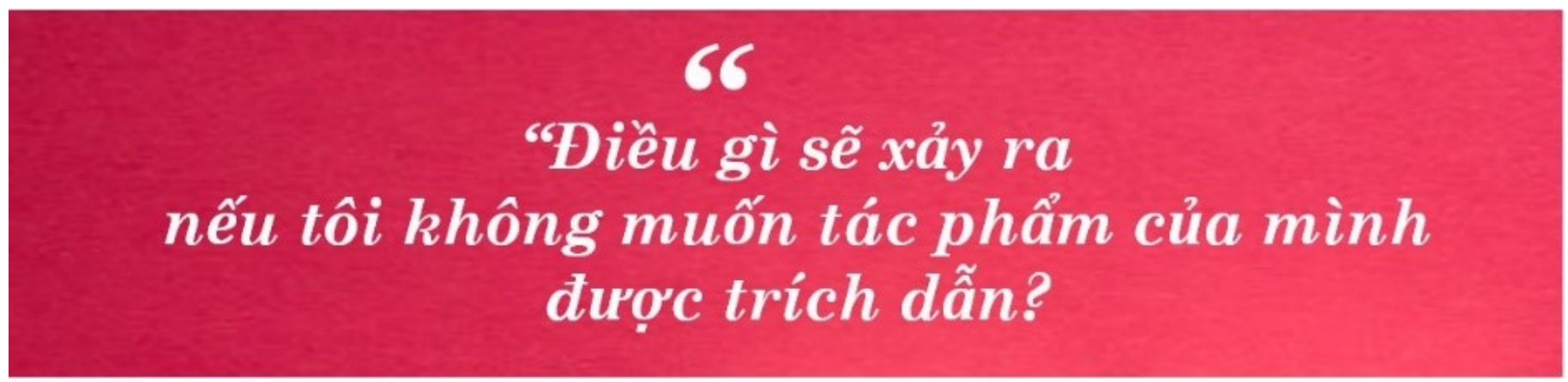

Điều này có thể xảy ra bởi vì các nhà khoa học, bao gồm cả các biên tập viên, có xu hướng xem các trích dẫn, không bao gồm các vòng trích dẫn và sự pha tạp và xếp chồng trích dẫn, như một hình thức khen thưởng hoặc công nhận trí tuệ.

Bài báo này nêu bật một số lo ngại liên quan đến các thực hành trích dẫn hiện nay: được trích dẫn trong một tạp chí chất lượng thấp hoặc có tính chất "săn mồi”, được trích dẫn bởi các tác giả giả mạo hoặc được trích dẫn không chính xác. Do đó, các tác giả đã tranh luận về quyền của tác giả từ chối các trích dẫn không mong muốn. Trên thực tế, quyền này rất khó thực hiện trong điều kiện hiện nay.

Để thực hiện quyền này sẽ đòi hỏi một sự thay đổi lớn trong văn hóa khoa học xung quanh việc trích dẫn, bắt đầu bằng việc suy nghĩ lại về $n$ nối ám ảnh hiện tại với các chi số tạp chí, JIF và xếp hạng trích dẫn vì một tư duy như vậy có thể chỉ kéo dài các hành vi xấu trong khoa học.

\section{6}

There is a diference between shoddy and highquality science. Similarly, there is a diference between a shoddy and a high-quality citation.

Việc loại bỏ các trích dẫn kém chất lựng có thể nâng cao chất lượng khoa học, giảm chi phí cho việc nghiên cứu khoa học và nâng cao lòng tin đối với giới học thuật. Thách thức trong tương lai sẽ là phân biệt rõ ràng cả hai loại trích dẫn, đặc biệt là khi số lượng trích dẫn từ các tạp chí được coi là chất lượng cao theo truyền thống trở nên lẫn lộn trong các tài liệu đã xuất bản.

Bây giờ là lúc để bắt đầu một cuộc trò chuyện hay tranh luận về vấn đề này. 
Nguồn: Jaime A. Teixeira da Silva, Quan-Hoang Vuong (2021). The right to refuse unwanted citations: rethinking the culture of science around the citation. Scientometrics. https://doi.org/10.1007/s11192-021-03960-9.

Luợc dịch, giới thiệu: Lương Ngọc

Ghi chú: Những quan điểm của tác giả không hẳn là quan điểm của Tạp chí Giáo dục.

Bạn đang đọc bài viết Quyền từ chối trích dẫn - phải chăng là một sự đi ngược lại với văn hoá trích dẫn khoa học? tại chuyên mục Thông tin khoa học của Tạp chí Giáo dục. Mọi thông tin góp ý và chia sẻ, xin vui lòng liên hệ SĐT: $(+84) 2437345363$ hoặc gửi về hòm thư tapchigiaoduc@moet.gov.vn 
